\section{All in The Book}

SIR - Creationism is on the march again, not only in the United States, but, as the letter from the Glasgow creationists shows (Nature 26 November 1981, p.302), in the United Kingdom as well. For a concept as theoretically and scientifically destitute as creationism, it is surprising to many that the idea keeps coming back. It seems to have the resilience of herpes.

It is neither easy nor much fun to argue with such grass-roots ignorance in a calm and civil manner. Consequently, lest the following comments be construed as arrogant, condescending, and supercilious, I trust that the Glasgow group will take them with good spirits. The Scots are, after all, renowned for their spirits.

Why do these people channel their vast intellectual energies against the innocuous theory of evolution? Why not against the pernicious satanic forces of quantum mechanics or particle physics? Why do they insist upon biblical literalism only in this specific case? After all, Leviticus 11:19 classifies the well-known mammal, the bat, as a bird. Jesus Christ (in Luke 23:43) says to his friends on the cross, "Today you will be with me in paradise," but everybody knows he did not show up in paradise himself until three days later. Why should anyone want to take Genesis 1 more literally?

Nineteen centuries ago, Josephus wrote that Moses "speaks some things wisely, yet enigmatically, and others allegorically", (Antiquities of the Jews, Preface, 4). Slightly later, the early Church father Origen wrote in his De Principiis (IV,i,5): "Who that has understanding will regard the statement as truthful that the first three days existed without Sun, Moon, and stars; and the first day without even a sky? And who is so ignorant as to suppose that God, as if a husbandman, planted a real tree in Eden such that anyone eating of it with bodily teeth should obtain life, and, eating of another tree, should come to the knowledge of good and evil? . . . No one, I think, can doubt that (these things) are related figuratively, not literally, in Scripture, and some mystical meaning may be indicated by it."

A single millennium after that (and before now) Maimonides concluded (Guide for the Perplexed, II, xxv): "If we accepted the Eternity of the Universe . . . and assumed, with Plato, that the heavens are likewise transient, we should not be in opposition to the fundamental principles of our religion." If the Bible was taken figuratively by scholars tens of centuries ago, who presumes to assert that it must now be taken at face value? What new information affirms the inerrancy of the Bible more now than in the time of Christ or Aquinas?

As a work of mythology and moral precepts, the Bible is probably as good as anybody's . . . except, of course, where Jael kills Sisera by nailing his head to the floor, Dinah is raped by Shechem and Lot is seduced by his own daughters. However, the Bible is neither among the most original nor imaginative of such works, as a glance through the mythology of nearly any culture on Earth will quickly reveal.
Nevertheless, those fatuous enough to require a biblical justification for everything, including evolution, might turn to Ecclesiastes 3:19 - "For that which befalleth the sons of men befalleth beasts . . . As the one dieth, so dieth the other; yea, they have all one breath; so that man hath no pre-eminence above a beast, for all is vanity. All go unto one place; all are of the dust, and all return to dust.'

The creationists claim that we may come to know the Creator by deducing Him from his work on Earth. Well, we know that there are 750,000 species of insect now alive. Anyone who has ever had a conversation with an entomologist knows what a deadly dull lot those fascinated by insects can be. To envision the Creator expending his divine energy on three-quarters of a million different, meticulously crafted bugs necessitates an image of Him as a dismal, insufferable, cosmic bore!

The patterns of the history of life also argue eloquently about the Creator's revelation of himself. As Haldane put it half a century ago: "Most lines of descent end in extinction, and commonly the end is reached by a number of different lines evolving in parallel. This does not suggest the work of an intelligent designer, still less of an almighty one."

Similarly, the fact that humans and chimpanzees hold more than 97 per cent of their genetic material in common should suggest that either they have evolved from a recent common progenitor, or that they were zapped into existence independently by Someone lacking a great deal of imagination.

The belief in such an Omnipotent Simpleton is certainly a matter of personal choice, but his existence (or lack thereof) is completely independent of the reality of evolution. For the natural world all but cries out for us to acknowledge phylogenetic relationships, and these relationships will be equally real to science whether or not deities exist.

Thus, evolution is not atheistic; it is agnostic. The existence of deities is not denied by evolution - it is ignored, because it is irrelevant. The study of evolution is the study of the diversity and unity of known life; the existence of God is as relevant to evolution as the existence of giant boll weevils on the planet Antares. Either things have evolved, or they are designed to appear to have evolved either way, science leads to the conclusion of evolution; the only paths to non-evolution are fraud and obscurantism.

Finally, one need only compare the last page of the first and sixth editions of The Origin of Species to see that even Darwin never completely ruled God out.

Well, everybody makes mistakes. JON MARKS

Department of Anthropology, University of Arizona,

Tucson, Arizona, USA

\section{Safe as 2,4,5-T?}

SIR - One of us (H.F.T.) reported last year on 2,4,5-T use and congenital abnormality rates in Hungary ${ }^{1}$. Since that report more information has become available on the herbicide used and on congenital abnormality and spontaneous abortion rates.
The Hungarian herbicide is applied either as Klorinol, the 2,4,5-T precursor, 2,4,5-trichlorphenoxyethanol $(2,4,5-\mathrm{TE})$, or as Buvinol, a combination of $2,4,5$-TE with $S$-triazine. Buvinol is one of the most important products of the Budapest Chemical Works, which marked its 100 th anniversary by publishing a book about it entitled The Development of a Pesticide as a Complex Scientific Task ${ }^{2}$. This monograph was published "as a tribute to the skill and many years of painstaking work performed by the research team and to reflect the standard and modern conditions of Hungarian pesticide research'" 2 . The editor suggests that the development of Buvinol "may be considered a real - even if not ideal - model of modern pesticide research"' 2 .

Development of the chlorinated phenoxy alkanols was conducted between 1962 and 1975. In 1969 contamination of 2,4,5-TE by dioxin (TCDD; 2,3,7,8-tetrachlorodibenzo-pdioxin) was discovered. The level of TCDD contaminant until mid-1972 was up to 1.6 p.p.m. After that date improvements in the formulated product reduced the TCDD contaminant to levels below 0.1 p.p.m. The extensive animal testing of 2,4,5-TE and Buvinol included studies of acute toxicology, neurotoxicology, teratogenicity and carcinogenicity 2 . Chromosomal studies were also undertaken of workers manufacturing 2,4,5-TE and Buvinol2. The general conclusion reached on the basis of all these studies was that if proper labour safety measures were taken and the relevant regulations for residues observed, no health hazard would arise. The production and consumption of 2,4,5-TE in Hungary has therefore continued to rise. In 1976, 1977 and 1978 consumption of $2,4,5-T E$ (total product) was $1,278,1,533$ and 1,753 tonnes respectively ${ }^{3}$. Trends in congenital anomalies and stillbirths have continued as described previously ${ }^{1}$ despite rising herbicide consumption.

Between 1970 and 1980, there has also been a consistent fall in the national spontaneous abortion rate (16.3 to 11.8 per cent of all recorded conceptions, excluding those terminated by induced abortion). The highest rates of fetal deaths occur in Budapest and the lowest in the country areas. There have been no reports in Hungary linking congenital abnormalities or spontaneous abortions with the use of 2,4,5-TE. Furthermore, a study of female agricultural workers exposed to 2,4,5-TE found no evidence that their offspring had a higher rate of congenital abnormalities 4 .

H.F. THOMAS

MRC Epidemiology Unit, Cardiff, UK

Department of Human Genetics, National Institute of Hygiene, Budapest, Hungary

Thomas, H.F Lancet ii, 214-215 (1980).

2. Banki, L. (ed.) The Development of a Pesticide as a Complex Scientific Task (Budapest Chemical Works, Medicina, 1976)

3. Food and Agricultural Organisation. Production Yearbook 1979 (FAO, Rome, 1979).

4. Szabuka, M. et al. Magy Noorv. Lap. 43, 527-534 (1980). 